\title{
Survey on Zoonotic Importance and Prevalence of Dirofilaria immitis Infection in Dogs of Tabriz, Iran
}

\author{
Hossein Hashemzadeh Farhang ${ }^{1 *}$, Seyed Razi Bahavarnia ${ }^{2}$, Mohamad Javad Esmailzadeh ${ }^{3}$, Navid Mahmoudi \\ Kamalabad $^{4}$
}

'Department of Pathobiology, Tabriz Branch, Islamic Azad University, Tabriz, Iran ${ }^{2}$ Department of Parasitology, Tabriz Branch, Islamic Azad University, Tabriz, Iran ${ }^{3}$ Faculty of Veterinary Medicine, Tabriz Branch, Islamic Azad University, Tabriz, Iran ${ }^{4}$ Faculty of Veterinary Medicine, Tabriz Branch, Islamic Azad University, Tabriz, Iran

\begin{abstract}
Background: Dirofilaria immitis is one of the most important parasites of the circulatory system of dogs that causes severe cardiovascular events in the animal and it is reported to be the most common nematode in humans and dogs from many parts of Iran.

Methods: In order to investigate the presence of Dirofilaria immitis infection in Tabriz, Iran, a cross-sectional study was performed on 200 owned and stray dogs. The blood samples were analyzed using Knott method. The prevalence of $D$. immitis infection was reported to be $15 \%$ in owned dogs.

Results: The highest levels of infection were reported in dogs less than one year of age and the lowest in dogs aged over 9 years. In a statistical survey, there was a significant relationship between infection and gender.

Conclusion: According to the findings of this study, due to the presence of $D$. immitis infection in this region, the need for a more comprehensive examination and control of the infection in this region is emphasized.

Keywords: Zoonotic importance, Dirofilaria immitis, Dog, Tabriz
\end{abstract}

Received: December 8, 2019, Accepted: December 18, 2019, ePublished: January 1, 2020

\section{Introduction}

Dirofilaria immitis is a parasitic worm which resides in the cardiovascular system and is responsible for cardiopulmonary filariasis in dogs and humans. Adult worms live in the right ventricle of the heart, pulmonary artery, and posterior vena cava. In addition to dogs, foxes, coyotes, domesticated cats, minks, blue mice, sea lions, wild cats, and rarely humans host the parasites (1). The main pathogenesis of Dirofilaria immitis is attack to pulmonary arteries and induce lung lesions in human and animals. In some endemic areas in the united states, the prevalence of the disease is about $45 \%$, and the number of infected dogs in hyperendemic areas with a tropical climate is high $(2,3)$.

The first case of canine D. immitis infection in Iran was reported for a dog imported from America. It was believed that there was no infection in Iranian dogs, and only foreign dogs living in Iran could have this infection. However, in a study in the same year on Shahsavar stray dogs, it was revealed that $4 \%$ of these dogs have heart disease $(4,5)$. Another study reported an incidence of $26.7 \%$ for stray dogs in Meshkinshahr (6). In another study in Tabriz, $31.6 \%$ of stray dogs in the city were found to have heartworm infection (7). In a study, it was revealed that $17.5 \%$ of dogs in Tankabon were infected (8). Moreover, 34.6\% of dogs in Ardabil, 9.5\% in Shiraz, $8.4 \%$ of shepherd dog in Tabriz, 25\% in Urmia, $1.4 \%$ in Tehran, $52.41 \%$ in Gilan, $7.69 \%$ in Mazandaran, $15.38 \%$ in Golestan, $12.29 \%$ in Garmsar, 5\% in Kerman, $10 \%$ in Ahwaz, and $5.07 \%$ of the stray dogs in Mashhad were infected with it (9).

The present study showed that East Azarbayjan province is one of the most infected regions in Iran. Generally, the diagnosis of canine heartworm infection can be made on the basis of detecting $D$. immitis microfilaria in the blood sample. Additionally, molecular and serological tests (Elisa), imaging, electrocardiogram, and immunochromatography can be used for diagnosis (10). The present study aimed to survey the prevalence of D. immitis infection in dogs of Tabriz city in Iran.

\section{Materials and Methods}

This cross-sectional study was conducted during 6 months in Tabriz city, Iran, in 2017. A total of 200 dogs (100 domestic dogs and 100 guardian and domestic) were collected from 4 areas (north, south, east, and west) of Tabriz city.

Two milliliters of blood was taken from saphenous or 
cephalic veins of each dog to examine, count, and detect the microfilaria by Knott method. For this purpose, immediately after getting blood, $1 \mathrm{~mL}$ blood was mixed with $9 \mathrm{~mL}$ of formalin $2 \%$ and gently shaken to cause hemolysis. In the laboratory, blood samples were centrifuged at $1500 \mathrm{rpm}$ for 3 minutes, and after discharge, methylene blue was added with a ratio of 1:1000 and a droplet of sediment was transferred to a lamella which was tested with microfiller. Then, important characteristics of tested dogs including age, gender, race, use of dogs, geographical area, and sampling date were recorded.

Dogs were divided into 6 groups of less than one year, 1-3 years old, 3-5 years old, 5-7 years old, 7-9 years old, and older than 9 years. Data were analyzed using Chisquare test and Fisher's exact test.

\section{Results}

Blood samples were taken from 200 urban and rural dogs to detect microfilaria. The data presented in Table 1 shows that the prevalence of Dirofilaria immitis infection in guardian dogs is three times that of home owner dogs. The results of chi-square test showed a statistically significant difference between the two groups.

\section{Relationship Between Filariasis and Gender}

The information in Table 2 shows that the prevalence of Dirofilaria immitis infection in two genders was similar (200 dogs), and there was no statistically significant

Table 1. Frequency of Canine Dirofilaria Immitis Infection in 200 Dogs of Tabriz City

\begin{tabular}{lcc}
\hline $\begin{array}{l}\text { The Population of the Dogs } \\
\text { Examined }\end{array}$ & $\begin{array}{c}\text { Number of Dogs } \\
\text { Under Investigation }\end{array}$ & $\begin{array}{c}\text { Number of Infected } \\
\text { Dogs }\end{array}$ \\
\hline Town Guardian & 80 & $14(17.5 \%)$ \\
Town home owner & 20 & $1(5 \%)$ \\
Rural dogs (flock) & 100 & $5(15 \%)$ \\
\hline
\end{tabular}

difference between them, while in the urban population, it was $11 \%$ higher in male dogs, which was confirmed by chi-square test.

\section{Relationship Between Filariasis and Age}

Table 3 shows that the incidence of filariasis increases with age. The rate of Dirofilaria immitis infection was $2 \%$ in dogs less than one year old in urban population and it was $60 \%$ in dogs older than 9 years old, indicating a statistically significant difference.

\section{Discussion}

In the present study, based on the results, microfilaria was detected in $15 \%$ of the owned dogs of Tabriz city, which is significantly different from previous reports from Tabriz (31.6\%) and Meshginshahr (26.7\%). In addition to the number of animals tested in different studies, the time of examination and living condition of dogs can play a part in this difference $(11,12)$. In the present study, the prevalence of infection in urban dogs was higher than rural dogs .

The rate of Dirofilaria immitis infection was higher in stray dogs, whose environmental condition was more similar to that of stray dogs, than in domestic dogs $(17.5 \%$ vs. $5 \%)$. In several studies, there was a big difference between blood tests and autopsies in terms of the prevalence of $D$. immitis infection $(13,14)$.

In a recent study on 200 dogs, the rate of heartworm infection was $45 \%$ based on blood tests, while it was $84 \%$ in the autopsy of the same animal. The difference between the two varieties of tests (39\%) indicated that the infection was hidden. The lower prevalence of the heartworm infection in herding dogs may be attributed to their living environment. One of the epidemiologic factors in $D$. immitis infection is the lack of movement of dogs (15).

Some researchers showed that one of the effective factors in the epidemiology of Dirofilaria immitis was

Table 2. Relationship Between Gender and Canine Dirofilaria Immitis Infection in Dogs of Tabriz City

\begin{tabular}{|c|c|c|c|c|}
\hline The Population Under Investigation & Gender & Number of Dogs Under Investigation & Number of Infected Dogs & Infected Percentage \\
\hline Urban & Male & 70 & 14 & 20 \\
\hline Urban & Female & 30 & 3 & 9 \\
\hline Rural & Male & 80 & 4 & 5 \\
\hline Rural & Female & 20 & 5 & 1 \\
\hline Total & - & 200 & 26 & 13 \\
\hline
\end{tabular}

Table 3. Relationship Between Age and Dirofilaria Immitis Infection in 200 Dogs of Tabriz City

\begin{tabular}{|c|c|c|c|c|c|c|c|}
\hline & & \multicolumn{6}{|c|}{ Year } \\
\hline & & $<1$ & $1-3$ & 3-5 & $5-7$ & $7-9$ & $>9$ \\
\hline \multirow{2}{*}{ Urban } & Number of dogs under investigation & 40 & 30 & 10 & 10 & 7 & 3 \\
\hline & Infected percentage & $2 \%$ & $12 \%$ & $2 \%$ & $26 \%$ & $30 \%$ & $60 \%$ \\
\hline \multirow{2}{*}{ Rural } & Number of dogs under investigation & 15 & 35 & 25 & 15 & 5 & 5 \\
\hline & Infected percentage & - & - & $6 \%$ & $3 \%$ & $1 \%$ & $14 \%$ \\
\hline
\end{tabular}


the place where dogs were kept, and the rate of infection in outdoor dogs was twice that of dogs kept indoors. In the present study, a significant relationship was reported between age and rate of $D$. immitis infection in urban dogs $(16,17)$.

Dirofilaria immitis was found primarily in urban dogs, and in this group, the incidence of infection in dogs less than 1 year old was $2 \%$, and it was $60 \%$ in dogs older than 9 years old. Due to the long life span of the heartworm, the prolonged presence of microfilaria in the blood and insufficient secretion of mucosa in adult dogs, there is no doubt that contact with the infected host will increase the risk of infection. The survey conducted in Meshkinshahr city had the highest rate of infection in dogs older than 10 years $(56.8 \%)(18,19)$.

In a study, the rate of heartworm infection in dogs of 1-3 years of age was $6.31 \%$ and it was $56.4 \%$ in dogs of 7-11 years of age, which is consistent with the findings of the present study. In the case of gender and heartworm infection, of the 100 rural dogs investigated in this study, only 20 were female, while in urban dogs, this was significant and the infection rate was $80 \%$ in five and $80 \%$ of males, which was 5 times more than 20 females (1\%).

Similar studies in the rest of the world have shown such a relationship. For example, one study showed that the rate of heartworm infection was significantly higher in male dogs $(89.7 \%)$ than in female dogs $(10.3 \%)$. The reason for this is the effect of sex hormones on the infection. There was a significant correlation between urban breed and $D$. immitis infection; however, it may be due to other factors in this regard, including dog shelter, health management, and the use of dogs which were not considered as risk factors $(20,21)$.

\section{Conflict of Interests}

The authors declare that they have no conflict of interests.

\section{Ethical Issues}

In this research, ethical considerations have been fully observed.

\section{Acknowledgements}

We would like to express our deep gratitude to Islamic Azad University Tabriz Branch for offering valuable theoretical and practical assistances to the research team in the present study.

\section{Authors' Contribution}

HHF did writing and editing of the manuscript. SRB and MJE designed and did data collection. NMK designed, did data collection and statistical analysis.

\section{Funding}

The authors received no financial support for the research, authorship and publication of this article.

\section{References}

1. Akhtardanesh B, Hossein Radfar M, Voosough D, Darijani N. Seroprevalence of canine heartworm disease in Kerman, southeastern Iran. Comp Clin Path. 2011;20(6):573-7. doi: 10.1007/s00580-010-1035-0.

2. Meshgi B, Eslami A, Ashrafi Helan J. Epidemiological survey of blood filariae in rural and urban dogs of Tabriz. J Fac Vet Med Univ Tehran. 2012;57(4):59-63. [Persian].

3. Malmasi A, Hosseini SH, Aramoon M, Bahonar A, Seifi HA. Survey of canine Dirofilaria immitis infection in Caspian provinces of Iran. Iran J Vet Res. 2011;12(4):340-4. doi: 10.22099/ijvr.2011.87.

4. Bokaie S, Mobedi I, Mohbali A. Evaluation of the prevalence of Dirofilaria imitis in Meshkin shahr -north west Iran. Journal of Veterinary Research (J Vet Res), Faculty of Veterinary Medicine, University of Tehran. 1998,1,(2):23-26. [Persian].

5. Nelson CT, McCall JW, Rubin SB, Buzhardt LF, Dorion DW, Graham W, et al. 2005 Guidelines for the diagnosis, prevention and management of heartworm (Dirofilaria immitis) infection in dogs. Vet Parasitol. 2005;133(2-3):255-66. doi: 10.1016/j. vetpar.2005.07.008.

6. Jamali R, Hashemzadeh F. Investigation of stray dogs contamination in Tabriz city of Dirofilaria Immitis. Second National Congress of Transmissible diseases of Human and Animal; 1996; Mashhad.p. 179.

7. Eslami A, Ranjbar-Bahadori S. Diagnostic Methods of Helminth Infection. Garmsar, Iran: Islamic Azad University, Garmsar Branch Publications; 2004. p. 296. [Persian].

8. Javadi S, Hanifeh M, Tavassoli M, Dalir-Naghadeh B, Khezri A, Hadian M. Dirrofilariasis in Shepherd Dogs of High Altitudes Areas in West Azerbaijan-Iran. Vet Res Forum. 2011;2(1):53-7.

9. Öncel T, Vural G. Seroprevalence of Dirofilaria immitis in stray dogs in Istanbul and Izmir. Turk J Vet Anim Sci. 2005;29(3):7859.

10. Bowman DD. Georgis' Parasitology for Veterinarians. 9th ed. St. Louis: Saunders; 2009. p. 318-9.

11. Meshki B, Eslami A. Investigation on the filariosis of dog in Tehran area. JVet Res. 2000;55(4):53-6. [Persian].

12. Eslami A. Veterinary helminthology, Nematoda and Acanthocephala. Tehran: University of Tehran University; 1996:584-603. [Persian].

13. Soulsby EJL. Helminths, Arthropods and Protozoa of Domesticated Animals. London: Baillière, Tindall and Cassell; 1969.

14. Sosa NF, Silva D, Goncalves R, Peixoto PC, Serra FMN. Prevalence of Dirofilaraia immitis in dogs in the city of Belm, para assessed on the basis of microfilaraemia. Rev Bras Parasitol Vet. 1996;6(1):83-6.

15. Ranjbar-Bahadori S, Hekmatkhah A. A study on filariosis of stray dogs in Garmsar. J Vet Res. 2007;62(4):73-6. [Persian].

16. Razi Jalali MH, Alborzi AR, Avizeh R, Mosallanejad B. A study on Dirofilaria immitis in healthy urban dogs from Ahvaz, Iran. Iran J Vet Res. 2010;11(4):357-62.

17. Ranjbar-Bahadori S, Eslami A, Bokaic S. Evaluation of different methods for diagnosis of Dirofilaria immitis. Pak J Biol Sci. 2007;10(11):1938-40. doi: 10.3923/pjbs.2007.1938.1940.

18. Sadighian A. Helminth parasites of stray dogs and jackals in Shahsavar area, Caspian region, Iran. J Parasitol. 1969;55(2):372-4.

19. Sanjar M, Niak A, Khatibi S. Dirofilariasis in the dog in Iran. Vet Rec. 1969;52:204.

20. Razm Arayi N, Ebrahimi M, Amegi A. Report on the occurrence of Dirofilaria immitis in wild carnivores in the north of East Azarbayjan. Presented at: The Fourth National Congress on Transmissible Diseases Between Animal and Human; 2000; Tehran. p. 230.

21. Garedaghi Y, Raoof P. Investigation of infection with Dirofilaria immitis parasite in stray dogs in Tabriz city of Iran. J Livest Sci. 2017;8:38-42.

(C) 2020 The Author(s); This is an open-access article distributed under the terms of the Creative Commons Attribution License (http:// creativecommons.org/licenses/by/4.0), which permits unrestricted use, distribution, and reproduction in any medium, provided the original work is properly cited. 